Proc. of the 15th Int. Workshop on Slow Positron Beam Techniques and Applications, Prague, September 2-6, 2019

\title{
Controlling the Network Properties of Polymer Matrices for Improvement of Amperometric Enzyme Biosensors: Contribution of Positron Annihilation
}

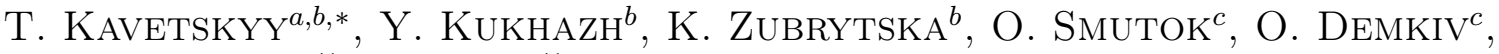

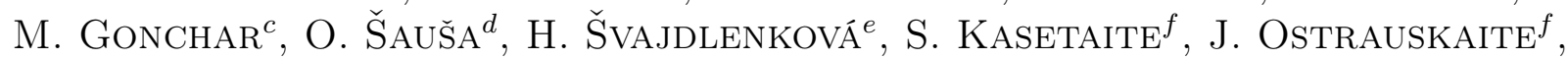 \\ V. Boev ${ }^{g}$, V. Ilcheva ${ }^{g}$ AND T. PetKova ${ }^{g}$ \\ ${ }^{a}$ The John Paul II Catholic University of Lublin, Al. Racławickie 14, 20-950 Lublin, Poland \\ ${ }^{b}$ Drohobych Ivan Franko State Pedagogical University, I. Franko Str. 24, 82100 Drohobych, Ukraine \\ ${ }^{c}$ Institute of Cell Biology, National Academy of Sciences of Ukraine, Drahomanov Str. 14/16, 79005 Lviv, Ukraine \\ ${ }^{d}$ Institute of Physics, Slovak Academy of Sciences, Dúbravská cesta 9, 84511 Bratislava, Slovak Republic \\ ${ }^{e}$ Polymer Institute, Slovak Academy of Sciences, Dúbravská cesta 9, 84541 Bratislava, Slovak Republic \\ ${ }^{f}$ Kaunas University of Technology, Radvilenu rd. 19, 50254 Kaunas, Lithuania \\ ${ }^{g}$ Institute of Electrochemistry and Energy Systems, Bulgarian Academy of Sciences, \\ Acad. G. Bonchev Str. Bl. 10, 1113 Sofia, Bulgaria

\begin{abstract}
Recent results obtained by studies on the network properties using positron annihilation lifetime spectroscopy and swelling measurements in the ureasil-based and photocross-linked polymer matrices are compared. Common features observed are the larger difference $\left(\alpha_{\mathrm{F} 2}-\alpha_{\mathrm{F} 1}\right)$ of the coefficients for the thermal expansion of free-volume holes $\alpha_{\mathrm{F} 1}, \alpha_{\mathrm{F} 2}$ below and above $T_{\mathrm{g}}$, respectively, in the polymer matrices, the highest sensitivity of the amperometric enzyme biosensors constructed based on the polymer matrices. It is suggested that the correlation found may be more general. It seems, therefore, that controlling the network properties of polymer matrices suitable for construction of amperometric enzyme biosensors by examining $\left(\alpha_{\mathrm{F} 2}-\alpha_{\mathrm{F} 1}\right)$ magnitude in temperature dependent positron annihilation lifetime spectroscopy experiment may be used for improvement of operational parameters of such sensors.
\end{abstract}

DOI: 10.12693/APhysPolA.137.246

PACS/topics: ureasil-based polymers, photocross-linked polymers, positron annihilation, biosensors

\section{Introduction}

The development of new approaches for monitoring xenoestrogens as the most dangerous pollutants of wastewater is a topical problem to improve human life first of all. To do that, the most promising candidate in analytical biotechnology seems to be amperometric biosensors - bioanalytical devices that combine the best features of bioelements (selectivity) and physical transducers (high sensitivity and accuracy). Establishment of the most suitable polymer matrices and nanocarriers for immobilization of enzymes and construction of improved amperometric biosensors of the "third generation" on the basis of the created biorecognition films is a challenge and needs a lot of efforts. In the present study the organic photocross-linked polymers and organic-inorganic hybrid ureasil-composite polymer matrices were used for immobilization of microbial laccase and construction of new prototypes of amperometric biosensors for potable water analysis with improved operational parameters (sensitivity, selectivity, stability, and reproducibility).

*corresponding author; e-mail: kavetskyy@yahoo.com
The knowledge of the properties of the microstructure of such polymer materials is important in terms of optimizing the regulated properties of the amperometric biosensors. A swelling test provides information about a crosslink density and flexibility of polymer network and is commonly used to characterize the structure of a crosslinked polymer. At the same time, positron annihilation lifetime spectroscopy (PALS) is known as a progressive method for microstructural analysis of macromolecular structures. Combination of both methods allowed to get information about network properties of the polymer matrices and the results obtained will be further compared with sensitivity of bioelectrodes constructed using the polymer matrices [1-5]. A role of free-volume and crosslink density in the host polymer matrices used for improvement of operational parameters of laccase-based amperometric biosensors would be established.

\section{Experimental}

Two types of polymers such as an organic-inorganic hybrid ureasilicate (shortened name - ureasil) and a photocross-linked polymer were selected for research. The synthesis of the ureasil-based polymers (pure ureasil and ureasil $/ \mathrm{As}_{2} \mathrm{~S}_{3}$ composite) was reported in [1-4]. 
The photocross-linked polymers based on the epoxidized linseed oil (ELO), bisphenol A diglycidyl ether (RD), and triarylsulfonium hexafluorophosphates used as photoinitiator $(\mathrm{PI})$ were synthesized by the reaction of ELO and $10 \mathrm{~mol} . \%$ or $30 \mathrm{~mol} \% \%$ of RD, using $3 \mathrm{~mol} . \%$ of PI (ELO/10RD and ELO/30RD) as reported in [5].

The temperature dependent PALS experiment was carried out as described in [2]. The lifetime spectra were taken using a ${ }^{22} \mathrm{Na}$ positron source with activity of $2 \mathrm{MBq}$ and analyzed with the free of charge LT Polymers program. The time resolution (FWHM) of spectrometer was about 320 ps, measured with a defect free Al sample. A three component fitting procedure with fixation of shortest component to 125 ps and theoretical ratio of relative intensities $I_{1} / I_{3}$ to $1 / 3$ was applied for lifetime data treatment. The longest lifetime component $\tau_{3}=\tau_{o-P s}$ ascribing to the ortho-positronium (o-Ps) pick-off annihilation in free-volume holes [6] were taken into account for analysis. The estimation of average free-volume hole size from measured $\tau_{3}$ was made by spherical approximation of hole shape by equation $[7,8]$ :

$$
\tau_{\mathrm{o}-\mathrm{Ps}}=0.5\left[1-\frac{R}{R+\Delta R}+\frac{1}{2 \pi} \sin \left(\frac{2 \pi R}{R+\Delta R}\right)\right]^{-1},
$$

where $\Delta R=0.166 \mathrm{~nm}$ is an empirical constant and $R$ is radius of spherical hole. Then $V_{\mathrm{h}}$ is given as

$$
V_{\mathrm{h}}=\frac{4}{3} \pi R^{3} \text {. }
$$

The temperature measurements were performed in the range of $15-350 \mathrm{~K}$ using a helium cryostat (Closed Cycle Refrigerator, Janis Research Company, Inc., USA) with an accuracy of $\pm 1 \mathrm{~K}$ and a vacuum equipment (Pfeiffer Vacuum, HiCUBE, Germany) with automatically controlled vacuum in the system. The samples were measured in "cooling-heating" cycles with $20 \mathrm{~K}$ steps of isothermic measurements and an elapsed time of $3-5 \mathrm{~h}$ per point to obtain an appropriate statistic error.

The samples with known weights were swollen in the anhydrous ethanol (EtOH) for both types of polymers. The swelling tests were performed during 8 days for the ureasil-based polymers and 2 days for the photocrosslinked polymers at room temperature. Details of swelling experiment were reported in $[2,4,5]$.

Biosensitive layers of the amperometric biosensor were formed on the surface of solid state transducers. In case of the ureasil-based polymers, planar gold electrodes DRP-C220AT from "DropSens" (Llanera, Asturias, Spain) were used as working electrodes [1, 3]. In case of the photocross-linked polymers, graphite rods (type RW001, $3.05 \mathrm{~mm}$ diameter, area $7.3 \mathrm{~mm}^{2}$, Ringsdorff Werke, Bonn, Germany) were used as working electrodes [5]. Immobilization of laccase was described for the ureasil-based polymers in [1, 3] and for the photocross-linked polymers in [5].

The estimation of the optimal working potential with cyclic voltamperometry and the conduction of an analysis with a chronoamperometric approach with respect to the corresponding substrate (2,2'-azinobis(3-ethylbenzothiazoline-6-sulphonic acid, ABTS) were performed for the constructed laccase-based amperometric enzyme biosensors of the third generation for analysis of phenol derivates using ureasil-based polymers $[1,3]$ and photocross-linked polymers [5].

\section{Results and discussion}

The temperature dependences $V_{\mathrm{h}}(T)$ were calculated from primary measured lifetime spectra for investigated samples. Figure 1 compares the temperature dependence of o-Ps lifetimes for ureasil-based polymers and two photocross-linked polymers.

The determined values of free-volume holes $V_{\mathrm{h}}$ at the glass transition temperature, glass transition temperature $\left(T_{\mathrm{g}}\right)$ thermal expansion coefficient $\left(\alpha_{\mathrm{F}}=\right.$ $\left.\left(1 / V_{\mathrm{h}}\right)\left(\Delta V_{\mathrm{h}} / \Delta T\right)[6]\right)$ of microscopical free-volume, and swellability $S$ for the ureasil-based polymers are gathered in Table I $[2,4]$. The incorporation of $\mathrm{As}_{2} \mathrm{~S}_{3}$ clusters into ureasil matrix results in the decreasing the hole volume $V_{\mathrm{h}}$ at glass transition temperature $T_{\mathrm{g}}$ and increasing $T_{\mathrm{g}}$, difference $\left(\alpha_{\mathrm{F} 2}-\alpha_{\mathrm{F} 1}\right)$ of the coefficients for the thermal expansion of free-volume holes $\alpha_{\mathrm{F} 1}, \alpha_{\mathrm{F} 2}$ below and above $T_{\mathrm{g}}$, respectively, and swellability $S$.

Analyzing the parameters of amperometric enzyme biosensors constructed based on the ureasil-based polymer matrices (Table II $[1,3]$ ), the main effect of $\mathrm{As}_{2} \mathrm{~S}_{3}$ clusters on the biosensor's sensitivity is found to be unexpectedly too strong, i.e., the biosensor's sensitivity is 50 times higher for the ureasil $/ \mathrm{As}_{2} \mathrm{~S}_{3}$ composite compared to the unmodified material.

The determined values of free-volume holes $V_{\mathrm{h}}$, glass transition temperature $T_{\mathrm{g}}$, thermal expansion coefficient of microscopical free-volume $\alpha_{F}$, and swellability $S$ for the photocross-linked polymers are shown in Table III [5].

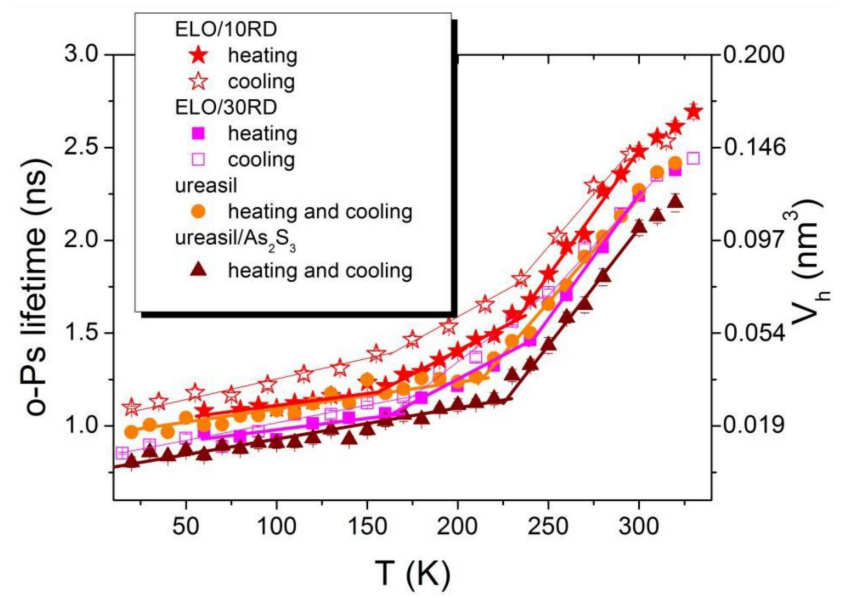

Fig. 1. Temperature dependence of o-Ps lifetimes for ureasil-based polymers (no difference between heating and cooling regimes) and two photocross-linked polymers (hysteresis is presented). The right horizontal axis shows the free volume of the holes for comparison. 


\section{TABLE I}

Hole volume $V_{\mathrm{h}}$ at glass transition temperature $T_{\mathrm{g}}$, slopes $\alpha_{\mathrm{F} 1}, \alpha_{\mathrm{F} 2}$ of the $V_{\mathrm{h}}(T)$ dependences in the regions below and above $T_{\mathrm{g}}$, respectively, as well as their differences $\left(\alpha_{\mathrm{F} 2}-\alpha_{\mathrm{F} 1}\right)$, and swellability $S$ in EtOH for the ureasil-based polymers $[2,4]$.

\begin{tabular}{l|c|c|c|c|c|c}
\hline \hline \multicolumn{1}{c|}{ Sample } & $V_{\mathrm{h}}\left(T_{\mathrm{g}}\right)\left[\mathrm{nm}^{3}\right]$ & $T_{\mathrm{g}}[\mathrm{K}]$ & $\alpha_{\mathrm{F} 1}\left[10^{-4} \mathrm{~K}^{-1}\right]$ & $\alpha_{\mathrm{F} 2}\left[10^{-4} \mathrm{~K}^{-1}\right]$ & $\alpha_{\mathrm{F} 2}-\alpha_{\mathrm{F} 1}\left[10^{-4} \mathrm{~K}^{-1}\right]$ & $S[\%]$ \\
\hline ureasil $(\mathrm{c}, \mathrm{h})$ & 0.035 & 216 & 25 & 286 & 261 & 23.50 \\
ureasil $/ \mathrm{As}_{2} \mathrm{~S}_{3}(\mathrm{c}, \mathrm{h})$ & 0.027 & 227 & 48 & 344 & 296 & 24.14 \\
\hline
\end{tabular}

$\mathrm{c}$ - cooling, $\mathrm{h}$ - heating

TABLE II

Biosensor response $I_{\max }$, apparent Michaelis-Menten constant $K_{M}^{\text {app }}$ toward ABTS as the substrate, the slope of the calibration curve $B$, the sensitivity of bioelectrodes (working surface area $12.6 \mathrm{~mm}^{2}$ ) constructed based on laccase immobilized by the ureasil-based polymers, and the range of linearity of the constructed bioelectrodes to ABTS [1, 3].

\begin{tabular}{l|c|c|c|c|c}
\hline \hline \multicolumn{1}{c|}{ Polymers } & $I_{\max }[\mu \mathrm{A}]$ & $K_{M}^{\text {app }}[\mathrm{mM}]$ & $B\left[\mu \mathrm{A} \mathrm{mM}^{-1}\right]$ & $\begin{array}{c}\text { Sensitivity } \\
{\left[\mathrm{A} \mathrm{M}^{-1} \mathrm{~m}^{-2}\right]}\end{array}$ & $\begin{array}{c}\text { Range of } \\
\text { linearity }[\mathrm{mM}]\end{array}$ \\
\hline ureasil & 7.62 & 0.64 & 10.0 & 794 & $0.0-0.15$ \\
ureasil $/ \mathrm{As}_{2} \mathrm{~S}_{3}$ & 43.77 & 0.045 & 501.7 & 39817 & $0.0-0.04$
\end{tabular}

TABLE III

Hole volume $V_{\mathrm{h}}$ at glass transition temperature $T_{\mathrm{g}}$, slopes $\alpha_{\mathrm{F} 1}, \alpha_{\mathrm{F} 2}$ of the $V_{\mathrm{h}}(T)$ dependences in the regions below and above $T_{\mathrm{g}}$, respectively, as well as their differences $\left(\alpha_{\mathrm{F} 2}-\alpha_{\mathrm{F} 1}\right)$, and swellability $S$ in EtOH for the photocross-linked polymers [5].

\begin{tabular}{c|c|c|c|c|c|c}
\hline \hline Sample & $V_{\mathrm{h}}\left(T_{\mathrm{g}}\right)\left[\mathrm{nm}^{3}\right]$ & $T_{\mathrm{g}}[\mathrm{K}]$ & $\alpha_{\mathrm{F} 1}\left[10^{-4} \mathrm{~K}^{-1}\right]$ & $\alpha_{\mathrm{F} 2}\left[10^{-4} \mathrm{~K}^{-1}\right]$ & $\alpha_{\mathrm{F} 2}-\alpha_{\mathrm{F} 1}\left[10^{-4} \mathrm{~K}^{-1}\right]$ & $S[\%]$ \\
\hline ELO/10RD (c) & 0.068 & \multirow{2}{*}{233} & 3.31 & 11.16 & 7.85 & 2.49 \\
ELO/10RD (h) & 0.057 & & 3.53 & 13.02 & 5.09 \\
\hline ELO/30RD (c) & 0.049 & \multirow{2}{*}{245} & 3.87 & 8.96 & 5.09 & 24.81 \\
ELO/30RD (h) & 0.051 & & 3.47 & 12.42 & 8.95 & \multirow{2}{*}{} \\
\hline
\end{tabular}

$\mathrm{c}$ - cooling, $\mathrm{h}$ - heating

TABLE IV

Biosensor response $I_{\max }$, apparent Michaelis-Menten constant $K_{M}^{\text {app }}$ toward ABTS as the substrate, the slope of the calibration curve $B$, and the sensitivity of bioelectrodes (working surface area $7.35 \mathrm{~mm}^{2}$ ) constructed based on laccase immobilized by the photocross-linked polymers [5].

\begin{tabular}{c|c|c|c|c|c}
\hline \hline Polymers & $I_{\max }[\mu \mathrm{A}]$ & $K_{M}^{\mathrm{app}}[\mathrm{mM}]$ & $B\left[\mu \mathrm{A} \mathrm{mM}^{-1}\right]$ & $\begin{array}{c}\text { Sensitivity } \\
{\left[\mathrm{A} \mathrm{M}^{-1} \mathrm{~m}^{-2}\right]}\end{array}$ & $\begin{array}{c}\text { Range of } \\
\text { linearity }[\mathrm{mM}]\end{array}$ \\
\hline $\mathrm{ELO} / 10 \mathrm{RD}$ & 4.9 & 0.36 & 12.3 & 1.673 & $0.006-0.15$ \\
$\mathrm{ELO} / 30 \mathrm{RD}$ & 1.25 & 0.11 & 9.07 & 1.234 & $0.025-0.10$
\end{tabular}

The polymer ELO/10RD is characterized by the lower $T_{\mathrm{g}}$, the lower swellability or higher crosslink density, larger free volume holes, and the larger change in microscopical free-volume below and above $T_{\mathrm{g}}$ compared to the polymer ELO/30RD. The conflict between the lower $T_{\mathrm{g}}$ and a denser crosslinked system in the case of polymer ELO/10RD is probably due to the presence of weak physical bonds that may also play a significant role at network behavior, causing a more packed structure and reducing the network flexibility. Another possible explanation is the $S$ parameter distortion due to less suitable solvent interaction parameters, i.e., not sufficient interaction between solvent and packed crosslinked structure.
Analyzing the parameters of amperometric enzyme biosensors constructed based on the photocross-linked polymer matrices (Table IV [5]), the improvement of the biosensor's sensitivity and range of linearity is found for the polymer ELO/10RD used as a holding matrix.

Common features observed for both polymers examined are the larger difference $\left(\alpha_{\mathrm{F} 2}-\alpha_{\mathrm{F} 1}\right)$ of the coefficients for the thermal expansion of free-volume holes $\alpha_{\mathrm{F} 1}, \alpha_{\mathrm{F} 2}$ below and above $T_{\mathrm{g}}$, respectively, in the polymer matrices, the highest sensitivity of the amperometric enzyme biosensors constructed based on the polymer matrices. It is suggested that the correlation found may be more general. 
In addition, a change in microscopical free-volume below and above $T_{\mathrm{g}}$ represented by $\left(\alpha_{\mathrm{F} 2}-\alpha_{\mathrm{F} 1}\right)$ should be further tested as a possible control parameter in temperature dependent PALS experiment, which may be used for improvement of operational parameters of biosensors.

\section{Conclusion}

Summarizing the results obtained in this work, the larger difference $\left(\alpha_{\mathrm{F} 2}-\alpha_{\mathrm{F} 1}\right)$ is found as a reflection of the microstructural properties of polymer matrices, the highest sensitivity of the amperometric enzyme biosensors constructed based on the polymer matrices. It is assumed that this microstructural characteristic of freevolume holes in polymer network obtained with help of PALS should be further tested as a control parameter for improvement of functionality of amperometric enzyme biosensors. The reason of this correlation is still not understood. More studies are required to understand the internal arrangement of the polymer matrix as well as its dynamics. It is not possible to generalize that from the two systems studied and further research is going on.

\section{Acknowledgments}

This work was supported in part by the Ministry of Education and Science of Ukraine (projects \#0117U007142 to Y.K. and K.Z., \#0118U000297 and \#0119U100671 to T.K., Y.K., O.S., O.D., and M.G.), National Academy of Sciences of Ukraine in the frame of the ScientificTechnical Program "Smart sensor devices of a new generation based on modern materials and technologies" (project \#13 to O.S., O.D., and M.G.), Slovak Grant Agency VEGA (project $\# 2 / 0157 / 17$ to O.Š.), APVV (project \#16-0369 to O.S. and H.Š.), and National Science Fund of the Bulgarian Ministry of Education (project \#FNI-DN09/12-2016 to T.K., V.B., V.I., and T.P.). T.K. and Y.K. also acknowledge the SAIA (Slovak Academic Information Agency) for scholarship in the IPSAS within the National Scholarship Programme of the Slovak Republic.

\section{References}

[1] T. Kavetskyy, O. Smutok, M. Gonchar, et al., J. Appl. Polym. Sci. 134, 45278 (2017).

[2] T. Kavetskyy, O. Šauša, K. Čechová, et al., Acta Phys. Pol. A 132, 1515 (2017).

[3] T.S. Kavetskyy, O. Smutok, M. Gonchar, et al., NATO Sci. Peace Security Ser. B Phys. Biophys. 309, (2018).

[4] T.S. Kavetskyy, H. Švajdlenková, Y. Kukhazh, et al., NATO Sci. Peace Security Ser. B Phys. Biophys. 333, (2018).

[5] T. Kavetskyy, O. Smutok, O. Demkiv, et al., Eur. Polym. J. 115, 391 (2019).

[6] Y.C. Jean, Microchem. J. 42, 72 (1990).

[7] S.J. Tao, J. Chem. Phys. 56, 5499 (1972).

[8] M. Eldrup, D. Lightbody, J.N. Sherwood, Chem. Phys. 63, 51 (1981). 